\title{
Nasal eupnoeic inhalation of cold, dry air increases airway resistance in asthmatic patients
}

\author{
P. Fontanari, M-C. Zattara-Hartmann, H. Burnet, Y. Jammes
}

\begin{abstract}
Nasal eupnoeic inhalation of cold, dry air increases airway resistance in asthmatic patients. P. Fontanari, M-C. Zattara-Hartmann, H. Burnet, Y. Jammes. CERS Journals Ltd 1997.

ABSTRACT: The aim of this study was to establish a relationship between bronchial hyperreactivity to carbachol and reflex bronchomotor response to the activation of cold receptors in the nose, and also to examine whether any differences exist between asthmatic patients with or without symptoms of rhinitis.

The changes in interrupting resistance ( $R$ int) induced by nasal eupnoeic inhalation of cold $\left(-5^{\circ} \mathrm{C}\right)$ dry air were measured in 22 normal subjects and in 18 asthmatic patients (nine of whom had asthma with rhinitis and nine without) with bronchial hyperreactivity to carbachol.

In normal individuals, nasal cold air challenge induced a significant increase in Rint $(+31 \%)$. This was also the case in asthmatic patients (asthma with rhinitis $+49 \%$; asthma alone $+\mathbf{4 0 \%}$ ), but the increase was not significantly larger than for normal individuals. The magnitude of $R$ int increase induced by nasal cold air breathing was correlated with the sensitivity to carbachol (defined as the dose inducing a 50\% increase in specific airway conductance (D50)) in asthmatic patients with symptoms of rhinitis.

These observations suggest that airway hyperreactivity is associated with enhanced bronchoconstrictor response to the activation of nasal cold receptors, particularly when rhinitis is present.
\end{abstract}

Eur Respir J 1997; 10: 2250-2254.
Laboratorie de Physiopathologie Respiratoire EA2201, Institut Jean Roche, Faculté de Médecine, Université de la Méditerrannée, Marseille, France.

Correspondence: Y. Jammes

Laboratoire de Physiopathologie Respiratoire EA2201

Faculté de Médecine

Bd Pierre Dramard

13916 Marseille cedex 20

France

Keywords: Bronchial hyperreactivity bronchomotor control

cold receptors

normal man

nose

Received: November 261996

Accepted after revision July 121997

This present study was supported by a grant from Association Française contre les Myopathies (AFM).
In a previous study in normal individuals [1], we demonstrated the existence of a nasopulmonary bronchoconstrictor reflex in response to nasal inhalation of cold $\left(-5\right.$ to $\left.-10^{\circ} \mathrm{C}\right)$ dry air during eupnoeic breathing. The afferent arm of this reflex was the trigeminal afferents of the nasal mucosa and the efferent arm was the vagus nerve, as demonstrated by the suppression of the airway response to cold air after nasal local anaesthesia or inhalation of an anticholinergic, respectively. In a recent review, McFADDEN [2] stated that "after lying dormant for several hundred years, the concept of a causal role for upper airway disease in the production of lower airway symptoms re-emerged, taking the new form of a nasobronchial reflex". Observations of a nasopulmonary bronchoconstrictor reflex in humans are often conflicting. Schumacher et al. [3] failed to demonstrate that nasal deposition of allergen or histamine caused a significant decrease in forced expiratory flow rates in subjects with asthma by a reflex mechanism. On the other hand, KAUFMAN and co-workers [4, 5] reported reflex bronchospasm after nasal irritation by silica particles, and YAN and Salome [6] found that histamine-induced nasal obstruction elicited a fall in forced expiratory volume in one second (FEV1) in subjects with perennial allergic rhinitis and stable asthma. Moreover, nasal cold challenge with freon-propelled aerosol induced a marked increase in oscillatory resistance in asthmatic patients, laryngectomized or not [7].
The aim of this study was to explore the nasopulmonary bronchoconstrictor response to cold air in patients who had atopic disease (asthma with or without associated symptoms of rhinitis) and bronchial hyperreactivity to carbachol. The magnitude of their airway response to cold air was compared to that measured in normal individuals of the same age. We tested the hypothesis that cold-induced increase in pulmonary resistance during nasal challenges could be accentuated in patients with bronchial hyperreactivity to carbachol, and also that this association could be enhanced when symptoms of rhinitis were present.

\section{Material and methods}

\section{Subjects and protocol}

Twenty two healthy subjects (4 females and 18 males) and 18 asthmatic patients with bronchial hyperreactivity to carbachol ( 7 females and 11 males) volunteered for this study. None of the healthy subjects were smokers and they had no antecedent symptoms of asthma, rhinitis or other atopic manifestations. All patients had stable asthma and eight also had symptomatic allergic rhinitis. However, no symptoms of rhinitis were reported at the time the lung function tests (including the nasal 
Table 1. - Morphological characteristics and lung function of subjects studied

\begin{tabular}{lcccccccc}
\hline Subjects & $\begin{array}{c}\text { Age } \\
\text { yrs }\end{array}$ & $\begin{array}{c}\text { Weight } \\
\mathrm{kg}\end{array}$ & $\begin{array}{c}\mathrm{Height} \\
\mathrm{cm}\end{array}$ & $\begin{array}{c}\text { VC } \\
⿱\end{array}$ & $\begin{array}{c}\mathrm{FEV} 1 / \mathrm{VC} \\
\%\end{array}$ & $\begin{array}{c}\mathrm{RV} / \mathrm{TLC} \\
\%\end{array}$ & $\begin{array}{c}\mathrm{s} G \text { aw } \\
\mathrm{cmH}_{2} \mathrm{O}^{-1} \cdot \mathrm{s}^{-1}\end{array}$ & $\begin{array}{c}R \text { int } \\
\mathrm{cmH}_{2} \mathrm{O} \cdot \mathrm{L}^{-1} \cdot \mathrm{s}\end{array}$ \\
\hline $\begin{array}{l}\text { Normal } \\
\mathrm{n}=22)\end{array}$ & $42 \pm 2$ & $70 \pm 3$ & $170 \pm 1$ & $4.7 \pm 0.2$ & $82 \pm 2$ & $32 \pm 2$ & $0.160 \pm 0.013$ & $3.1 \pm 0.2$ \\
$\begin{array}{l}\text { With BHR } \\
(\mathrm{n}=18)\end{array}$ & $35 \pm 5$ & $71 \pm 7$ & $167 \pm 3$ & $4.3 \pm 0.3$ & $81 \pm 1$ & $33 \pm 2$ & $0.119 \pm 0.008 *$ & $3.6 \pm 0.3$ \\
\hline
\end{tabular}

Values are presented as mean \pm SEM. $\ddagger$ : corrected to body temperature, atmospheric pressure and saturation with water vapour (BTPS). VC: vital capacity; FEV1/VC: ratio of forced expiratory volume in one second to VC; RV/TLC: ratio of residual volume to total lung capacity; sGaw: specific airway conductance; Rint: interrupting resistance; BHR: bronchial hyperresponsiveness. *: $\mathrm{p}<0.05$, significant difference between baseline s $G$ aw measured in normal subjects and in asthmatic patients.

cold challenge) were performed. Thus, no patients received any specific therapeutic agents, such as antihistamines, nasal steroids, cromolyn or ipratropium bromide, for at least 1 month.

Table 1 shows the functional characteristics of the subjects. As stipulated by the Institutional Human Subjects Committee, the subjects were fully informed of all procedures and written consent was obtained, however they remained unaware of the purpose of the study. Before trial, we measured control values of interrupting resistance (Rint), to assess the changes in airway resistance throughout nasal inhalation of cold, dry air. $R$ int measurements were repeated every 5 min during a 15 min period of cold air breathing and a $10 \mathrm{~min}$ period of recovery, during which the subjects inhaled room air. To measure Rint during nasal inhalation of cold air, the subjects breathed once via the nose and twice via the mouth to maintain nasal stimulations between two successive Rint measurements.

\section{Methods}

Assessment of airway reactivity to carbachol. On separate days, a dose-response curve was obtained in each individual by plotting the value of specific airway conductance ( $\mathrm{s} G$ aw) measured in a whole-body plethysmograph by the method of DuBors et al. [8] against cumulative doses of carbachol in the range 100-2,000 $\mu \mathrm{g}$. Sensitivity to carbachol was defined as the dose inducing a $50 \%$ increase in sGaw (D50), and reactivity was the slope of the sGaw vs carbachol dose relationship [9]. Subjects were considered as hyperreactive to carbachol when D50 was $\leq 800 \mu \mathrm{g}$. Fourteen asthmatic patients had a D50 value $\leq 500 \mu \mathrm{g}$.

Measurements of respiratory variables. The experimental set-up was the same as that used previously [1]. Measurements were always performed in comfortably seated subjects. In all cases, subjects inhaled cold $\left(-5^{\circ} \mathrm{C}\right)$ and dry air (relative humidity (RH) $0.3 \%$ ) via a two-way valve (dead space $5 \mathrm{~mL}$ ), which avoided contamination of inspired air by expired gas. During nasal breathing, the subjects wore a mask (dead space $=140 \mathrm{~mL}$ ) firmly adjusted to the nose. For Rint measurement, the subject breathed through the mouth in a grid pneumotachograph connected to the interrupting device, consisting of a throttle valve with an electromanometer to measure mouth pressure (Masterscreen, Hellige-Jaeger, Switzerland). After every two breaths, a single $100 \mathrm{~ms}$ occlusion was performed at $50 \%$ of expired tidal volume. Thus, Rint was always measured at mid-tidal expiratory flow.
During room air breathing or inhalation of conditioned air the subjects breathed in time with a metronome at 15 breaths min $^{-1}$. This minimized mechanical artefacts due to the eventual change in breathing pattern during cold, dry gas inhalation. It was verified that end-tidal carbon dioxide tension was the same both in conditions of room air or cold air breathing, in order to avoid the eventual bronchomotor consequences of a slight hypocapnia. Temperatures were measured with type $\mathrm{K}$ chromel-alumel thermocouples (time constant $0.1 \mathrm{~s}$ ) and read on a digital voltmeter. Inspired temperature was measured just before the two-way valve $3 \mathrm{~cm}$ from of the inlet of the mask. A thermohygrometer (time constant 3 s) (Quick Novo, Bioblock Scientific, Strasbourg, France) was placed in the inspiratory line of the circuit. $\mathrm{RH}$ values were read on a digital voltmeter.

Experimental set-up used to modify inspired air temperature and/or humidity. As described already [1], compressed air at a flow rate of $30 \mathrm{~L} \cdot \mathrm{min}^{-1}$ was dried by passing through a calcium chloride column, and then cooled at $-5 \pm 1^{\circ} \mathrm{C}$ using a low resistance circuit comprising a copper spiral immersed in a glycol bath, placed in a commercial freezer. A four-way stopcock made it possible to divert conditioned air to the inspiratory circuit or the room. Mask pressure changes were less than $1 \mathrm{cmH}_{2} \mathrm{O}$ when the stopcock was turned on the compressed air circuit.

\section{Analysis}

After verifying the normality of data distribution (Kolmogorov-Smirnov test), one-way repeated measures analysis of variance (ANOVA) was used to test for differences in the effects of a series of experimental conditions on the same group of subjects, by examining the changes in each individual. When ANOVA indicated the existence of a significant difference $(p<0.05)$ within the present experimental conditions, Dunnett's method was used as post-ANOVA multiple comparison test. Student's t-test was used to compare mean change in ( $\Delta)$ Rint between: 1) healthy subjects and patients; and 2) patients suffering from asthma alone or also presenting clinical symptoms of rhinitis.

\section{Results}

Table 1 shows that sGaw was significantly lower in patients compared to normal subjects. This was not the case for Rint values, but this method is well known to 
have poorer sensitivity for detecting bronchoconstriction than standard techniques [10]. No significant differences were found between patients with or without rhinitis.

Figure 1 shows that in normal subjects, Rint increased significantly during nasal cold air challenge $(+31 \pm 7 \%$; $\mathrm{p}<0.01)$. The airway response had a slight, nonsignificant tendency to adapt throughout the challenge $(+31 \%$, $+26 \%$ and $+16 \%$ at 5,10 and 15 min, respectively). Recovery of baseline Rint value was always noted 5 min after discontinuation of the cold air challenge. The airway response to nasal cold air challenge was analysed separately in asthmatic patients with or without symptoms of rhinitis. In both groups of asthmatic patients,

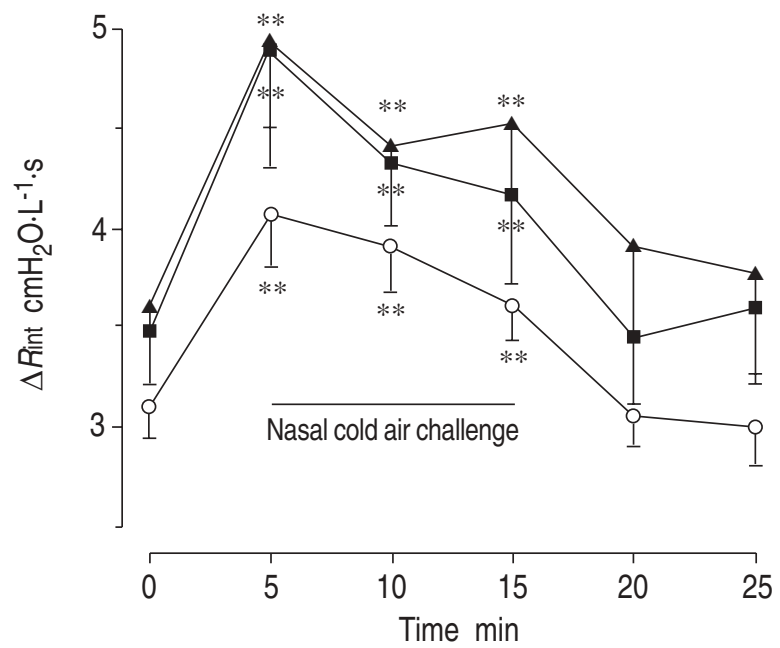

Fig. 1. - Absolute values of increases in interrupting resistance $(\Delta R$ int $)$ measured in normal individuals and asthmatic patients with or without symptoms of rhinitis in response to nasal eupnoeic inhalation of cold, dry air $\left(-5^{\circ} \mathrm{C}\right)$ and the first $10 \mathrm{~min}$ of the recovery period. In the three groups of subjects, significant Rint increases were measured (**: $\mathrm{p}<0.01$ ). Despite a tendency to enhanced airway response to cold air in asthmatic patients, the differences compared to the group of healthy volunteers were not significant. - - - : normal subjects; - : asthmatic subjects with rhinitis; _ـ : subjects with asthma alone. cold air-induced $\Delta R$ int tended to be accentuated (asthma with rhinitis $+49 \%$; asthma alone $+40 \%$ ), but the difference was not significantly larger than for normal subjects. A tendency for the airway response to adapt throughout the challenge was also noted. As in normal individuals, recovery of control $R$ int values was measured $5 \mathrm{~min}$ after the cold air test ended.

Figure 2 shows that only in those patients with asthma plus rhinitis was there a significant correlation ( $\mathrm{r}=-$ $0.830 ; \mathrm{p}<0.01$ ) between the magnitude of cold air-induced $\Delta R$ int and D50, i.e. the sensitivity to carbachol. No correlation was noted between $\Delta R$ int and the slope of s $G$ aw $v s$ carbachol dose relationship (data not shown). The individuals who presented the largest $\Delta R$ int in response to nasal cold dry air also reported a sensation of dyspnoea, which disappeared throughout the recovery period.

\section{Discussion}

The present observations confirm our previous data [1] concerning the existence of a nasopulmonary bronchoconstrictor response to cold dry air in normal subjects. In this group of asthmatic patients, the airway response to cold, dry air breathing was present and also accentuated. There was no significant difference in bronchoconstrictor response to nasal cold air challenge between patients with asthma plus rhinitis and those with asthma alone. A significant correlation was found between cold air-induced $R$ int changes and the individual sensitivity to carbachol (D50), the bronchomotor response to nasal inhalation of cold air being elevated in the most sensitive individuals. However, this association was only present in asthmatic patients who had presented frequent episodes of rhinitis.

As shown by PHAGOO et al. [10], the interrupter technique had poorer sensitivity for detecting bronchoconstriction than measurement of s $G$ aw using a body plethysmograph.
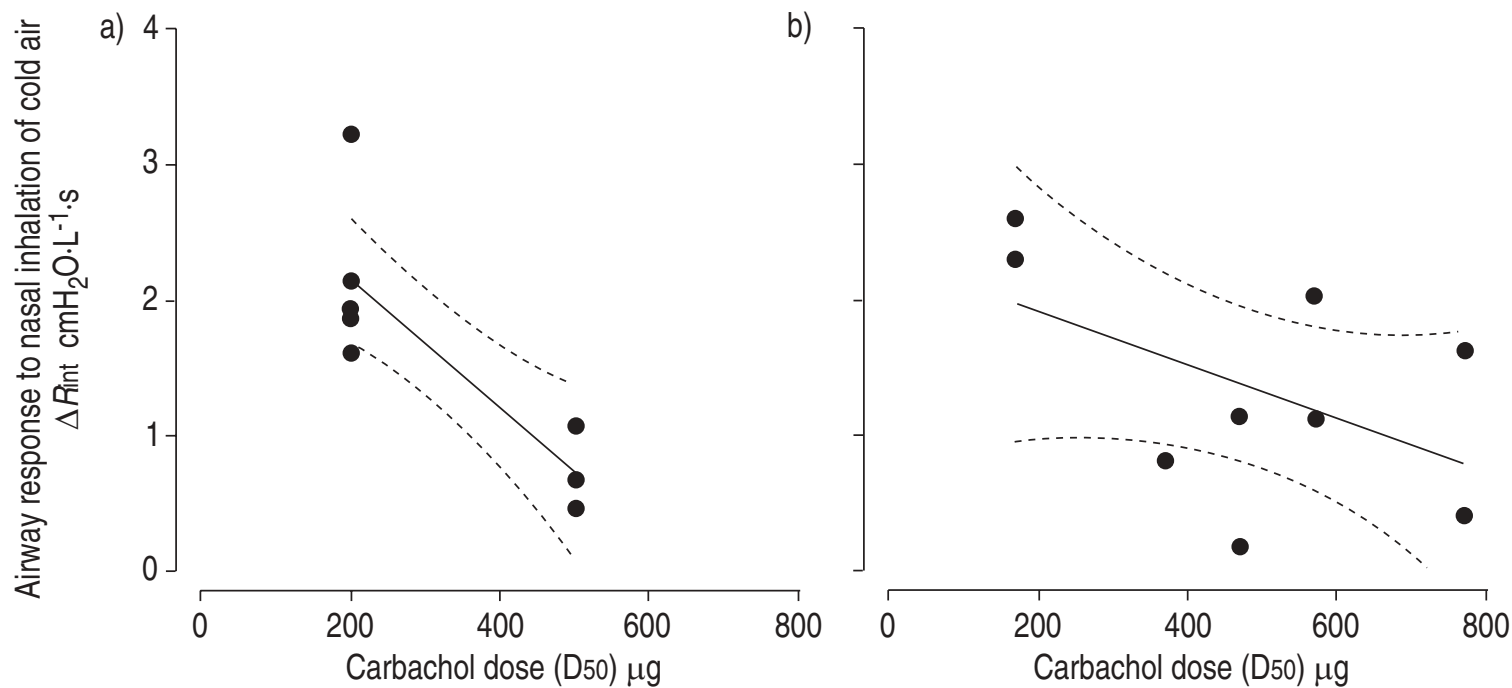

Fig. 2. - Correlation between increases in interrupting resistance ( $\Delta$ Rint) measured during nasal cold dry air inhalation and bronchial sensitivity (defined as the dose inducing a $50 \%$ increase in specific airway conductance (D50)) to carbachol: a) in subjects with asthma plus rhinitis; and $b$ ) in subjects with asthma alone. A significant linear correlation was found only in the group of asthmatic patients who presented symptoms of rhinitis $(r=-0.830 ; p<0.01: \Delta R$ int=3.09-4.73.D50), whereas the correlation was not significant when rhinitis was absent $(r=-0.520 ; p=0.15)$. Dotted lines show the $95 \%$ confidence intervals. 
However, in our protocol the use of a body plethysmograph would necessitate interruption of the nasal inhalation of cold air for several minutes, with the consequence of an adaptation of the cold-induced airway response during the period of sGaw measurement.

The changes in airway resistance in response to nasal inhalation of cold air in the present study are interpreted in terms of the reflex activation of trigeminal nasal afferents. Indeed, in normal individuals [1], Rint changes were always abolished by local anaesthesia of the nasal mucosa. This eliminates possible direct effects of cooling the airway mucosa. Melville and Morris [11] and BERK et al. [12] have also demonstrated that stimulation of cutaneous cold receptors elicited a bronchospasm. This reflex path is not activated in the present protocol of nasal inhalation of cold air because the airway response disappeared after local anaesthesia of the sole nasal mucosa.

Human studies by McFADDEN et al. [13] have clearly shown that the capacity of the upper airways to condition inspired air was overcome, with resulting direct cooling of the tracheal mucosa, only when subjects hyperventilate freezing air $\left(-19^{\circ} \mathrm{C}\right)$ through the mouth. Thus, during eupnoeic nasal breathing of moderately cold air $\left(-5^{\circ} \mathrm{C}\right)$ an increase in airway resistance may only result from a reflex mechanism initiated through the activation of cold-sensitive nerve endings in the upper respiratory tract. The existence of these cold receptors is documented in the larynx and upper trachea in animals $[14,15]$, and in the nose in animals [16, 17] and humans [1], and is suspected in the oropharynx in humans [18]. In our previous study [1], we eliminated the possibility of upper airway narrowing in response to activation of trigeminal afferents, as suggested by JounIEAux et al. [19], because prior inhalation of an anticholinergic abolished the changes in Rint in response to nasal cold challenge.

YAN and SALOME [6] found no relationship between the fall in FEV1 resulting from nasal stimulation by histamine and the reactivity of bronchial smooth muscles to histamine. By contrast, Nolte and Berger [7] reported that the nasopulmonary bronchoconstrictor response to a cold air stimulus applied to the nose was modest or absent in normal individuals, whereas it was marked in asthmatic patients. The present observations only partly confirm the data by Nolte and Berger [7], in the sense that we also measured a substantial $(+30 \%)$ cold air-induced increase in airway resistance in normal subjects. The differences in magnitude of airway responses between the two studies could result from the fact that nasal cooling lasted $15 \mathrm{~min}$ in the present investigation, whereas a single spray of freon-propelled aerosol of fluor-chlor and methane or ethane was used in the study by Nolte and Berger [7].

Our data suggest that in asthmatic patients, the airway response to nasal cold air challenge was more marked in some individuals who presented asthma plus symptoms of rhinitis. We have no explanation for the mechanism of this association because the nasal resistance was not measured in the present patients, and thus the nasal response to cold, dry air breathing could not be assessed. However, no symptoms of nasal obstruction occurred during the cold air challenge, and some subjects even reported an improvement of nasal inhalation.
The sole element of discussion is that enhanced reactivity of airway smooth muscle to bronchoconstrictor agents is often responsible for an elevated contractile response to any vagally mediated reflex, including that induced by the stimulation of cold receptors in the airways. Thus, in rabbits sensitized to bovine serum albumin [20], which developed bronchial hyperresponsiveness to histamine, the magnitude of cold-induced vagally-mediated bronchospasm was significantly higher than in nonsensitized animals. We concluded that sensitization by foreign proteins modified the intrinsic properties of the tracheal smooth muscle in the direction of enhanced contractile response to any activation of the vagal motor control, including the stimulation of bronchopulmonary C-fibres by phenyldiguanide. It may be hypothesized that the same phenomenon underlies the existence of enhanced bronchoconstrictor response to nasal inhalation of cold air in asthmatic patients.

The present data show that the nasopulmonary bronchoconstrictor reflex in response to inhalation of cold dry air was markedly accentuated in asthmatic patients with rhinitis, who presented a high sensitivity to carbachol (defined as the dose inducing a $50 \%$ increase in specific airway conductance). The increase in airway resistance may reach $3-4.6 \mathrm{cmH}_{2} \mathrm{O} \cdot \mathrm{L}^{-1} \cdot \mathrm{s}$ in some subjects, with an associated sensation of dyspnoea. This nasal cold air challenge could be proposed as a predictive method to assess the individual sensitivity to cold air in asthmatic patients who plan to ski or to participate in other snow sports.

\section{References}

1. Fontanari P, Burnet H, Zattara-Hartmann MC, Jammes $Y$. Changes in airway resistance induced by nasal inhalation of cold dry, dry or moist air in normal individuals. J Appl Physiol 1996; 81: 1739-1743.

2. McFadden ER Jr. Nasal-sinus-pulmonary reflexes and bronchial asthma. J Allergy Clin Immunol 1986; 78 : $1-3$.

3. Schumacher MJ, Cota KA, Taussig LM. Pulmonary response to nasal challenge testing of atopic subjects with stable asthma. J Allergy Clin Immunol 1986; 78 : 30-35.

4. Kaufman J, Wright GW. The effect of nasal and nasopharyngeal irritation on airway resistance in man. Am Rev Respir Dis 1969; 100: 626-629.

5. Kaufman J, Chen JC, Wright GW. The effect of trigeminal resection on reflex bronchoconstriction after nasal and nasoparyngeal irritation in man. Am Rev Respir Dis 1970; 101: 768-769.

6. Yan K, Salome C. The response of the airways to nasal stimulation in asthmatics with rhinitis. Eur J Respir Dis 1983; 64 (Suppl. 128): 105-108.

7. Nolte D, Berger D. On vagal bronchoconstriction in asthmatic patients by nasal irritation. Eur J Respir Dis 1983; 64 (Suppl. 128): 110-114.

8. DuBois AB, Botelho SW, Comroe JH. A new method for measuring airway resistance in man using a body plethysmograph: values in normal subjects and in patients. J Clin Invest 1956; 35: 327-335.

9. Orehek J, Gayrard P, Smith AP, Grimaud Ch, Charpin J. Airway response to carbachol in normal and asthmatic subjects: distinction between bronchial sensitivity and reactivity. Am Rev Respir Dis 1977; 115: 937-943. 
10. Phagoo SB, Watson RA, Silverman M, Pride NB. Comparison of four methods of assessing airflow resistance before and after induced airway narrowing in normal subjects. J Appl Physiol 1995; 79: 518-525.

11. Melville GN, Morris D. Cold: effect on airway resistance in health and disease. Environ Physiol Biochem 1972; 2: 107-116.

12. Berk JL, Lenner KA, McFadden ER Jr. Cold-induced bronchoconstriction: role of cutaneous reflexes vs direct airway effects. J Appl Physiol 1987; 63: 659664.

13. McFadden ER Jr, Pichurko BM, Bowman HF, et al. Thermal mapping of the airways in humans. $J$ Appl Physiol 1985; 58: 564-570.

14. Jammes Y, Nail B, Mei N, Grimaud Ch. Laryngeal afferents activated by phenyldiguanide and their response to cold air or helium-oxygen. Respir Physiol 1987; 67: 379-389.

15. Jammes Y, Barthelemy P, Delpierre S. Respiratory effects of cold air breathing in anesthetized cats. Respir Physiol 1983; 54: 41-54.

16. Tsubone H. Nasal "flow" receptors of the rat. Respir Physiol 1989; 75: 51-64.

17. Wallois F, Macron JM, Jounieaux V, Duron B. Trigeminal nasal receptors related to respiration and to various stimuli in cats. Respir Physiol 1991; 85: 111-125.

18. McNally JF Jr, Enright P, Hirsch JE, Souhrada JF. The attenuation of exercise-induced bronchoconstriction by oropharyngeal anesthesia. Am Rev Respir Dis 1979; 119: 247-252.

19. Jounieaux V, Aubert G, Dury M, Delguste P, Rodenstein DO. Effects of nasal positive-pressure hyperventilation on the glottis in normal awake subjects. J Appl Physiol 1995; 79: 176-185.

20. Badier M, Barthelemy P, Soler M, Jammes Y. In vivo and in vitro studies on cold-induced airway response in normal and sensitized rabbits. Respir Physiol 1988; 73: 1-10. 